Revista Thema

\begin{tabular}{l|l|l} 
V.20 & Especial 2021
\end{tabular}

p.17-36
DOI: http://dx.doi.org/10.15536/thema.V20.Especial.2021.17-36.1831

ISSN: 2177-2894 (online)

\title{
Educação remota em tempos da COVID-19:
} inquietações acerca da pessoa com deficiência e o Exame Nacional do Ensino Médio

\section{THEMA}

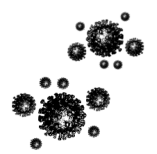

Remote education in COVID-19 times: concerns about the people with disabilities and the Brazilian's National High School Examination

Susana Lima de Queiroz Pontes de Araujo ${ }^{1}$,

Flávia Barbosa da Silva Dutra²

\begin{abstract}
RESUMO
O presente artigo tem como objetivo discutir os desmembramentos da educação neste período de distanciamento social, trazendo para o debate questões referentes à educação remota das pessoas com deficiência e as inquietações acerca do adiamento do Exame Nacional do Ensino Médio (ENEM). Questionamentos sobre a educação remota em tempos da COVID-19 impulsionaram a presente pesquisa. Para análise, foram utilizadas as Sinopses Estatísticas do ENEM entre os anos 2009 a 2018, fornecidas pelo Instituto Nacional de Estudos e Pesquisas Educacionais Anísio Teixeira (INEP), além de levantamento documental sobre o tema. As análises mostram que a educação remota em tempos da COVID-19 precisa levar em consideração diversos fatores como o acesso à internet e as especificidades dos estudantes com deficiência, bem como destaca a necessidade do adiamento do ENEM diante da realidade vivenciada.
\end{abstract}

Palavras-chave: Educação remota; estudante com deficiência; COVID-19; pandemia; ENEM.

\begin{abstract}
The present study about the dismemberment of education in this period of social distancing, bringing into debate issues regarding the remote education of people with disabilities and concerns about the postponement of the Brazilian's National High School Examination (ENEM). Questions about remote education during the COVID-19 pandemic drove this research. For this analysis, it was used the ENEM's Statistical Synopses between the years of 2009 to 2018, provided by the National Institute of Educational Studies and Research Anísio Teixeira (INEP), in addition to a documentary survey on the subject. The analyzes show that remote education during the COVID-19 pandemic needs to take into account several factors such as internet access and the specificities of students with disabilities, as well as highlighting the need to postpone ENEM in the face of the reality experienced.
\end{abstract}

Keywords: Remote education; disabled student; COVID-19; pandemic; ENEM.

\footnotetext{
${ }^{1}$ Universidade Federal do Rio de Janeiro - UFRJ, Rio de Janeiro/RJ - Brasil. E-mail: susylima.lima@gmail.com

${ }^{2}$ Universidade do Estado do Rio de Janeiro - UERJ, Rio de Janeiro/RJ - Brasil. E-mail: fbsdutra@gmail.com
} 


\section{INTRODUÇÃO}

O cenário mundial das interações sociais mudou drasticamente nos últimos meses. Medidas preventivas de distanciamento e isolamento social foram necessárias para diminuir o contágio pelo coronavírus (COVID-19). Em face a esta nova realidade as relações cotidianas, como trabalho, estudo e lazer, foram afetadas, objetivando conter a propagação do vírus e reduzir os possíveis números de vítimas da doença.

O presente artigo tem por objetivo discutir os desmembramentos da educação neste período de distanciamento social, trazendo para o debate as especificidades das pessoas com deficiência frente a esse modelo de educação que é apresentado durante a pandemia. Traremos também apontamentos sobre o impacto que a realização do ENEM em sua data originalmente programada poderia gerar ao ingresso desta população socialmente estigmatizada (DI BLASI; DUTRA; RUMJANEK, 2019) ao ensino superior. Para esta análise utilizamos de levantamento documental (GIL, 2002) sobre o tema e das Sinopses Estatísticas do Exame Nacional do Ensino Médio (ENEM) entre os anos 2009 a 2018, fornecidas pelo Instituto Nacional de Estudos e Pesquisas Educacionais Anísio Teixeira (INEP).

Diante das condições de distanciamento e da incerteza do retorno das atividades educacionais presenciais, o país se viu em um quadro de necessidade de adaptação, em busca de menor prejuízo ao aprendizado dos estudantes. Assim sendo, a educação através de meios digitais foi uma das soluções pensadas para levar os conteúdos programáticos a estes estudantes uma vez que as escolas encontram-se fechadas, inviabilizando a educação em sua prática presencial.

Neste sentido, com a urgência de "manter o funcionamento das escolas", as redes públicas e privadas começaram a desenvolver a educação remota, seja por videoaulas, plataformas educacionais, envio de atividades aos estudantes através das mídias sociais, etc. O intuito maior foi a garantia da carga horária mínima anual estabelecida na Lei de Diretrizes e Bases da Educação Nacional (LDB) n 9.694/96, que em seu artigo 24, inciso I prevê "oitocentas horas para o ensino fundamental e para o ensino médio, distribuídas por um mínimo de duzentos dias de efetivo trabalho escolar, excluído o tempo reservado aos exames finais, quando houver", uma vez que a Medida Provisória no 934, de $1^{\circ}$ de abril de 2020, estabelece normas excepcionais sobre o ano letivo, fixando a obrigatoriedade apenas na carga horária mínima anual de atividades educativas.

Art. 1 응 0 estabelecimento de ensino de educação básica fica dispensado, em caráter excepcional, da obrigatoriedade de observância ao mínimo de dias de efetivo trabalho escolar, nos termos do disposto no inciso I do caput e no $\S 1$ o do art. 24 e no inciso II do caput do art. 31 da Lei no 9.394, de 20 de dezembro de 1996, desde que cumprida a carga horária mínima anual estabelecida nos referidos dispositivos, observadas as normas a serem editadas pelos respectivos sistemas de ensino. (BRASIL, 2020, p.1, grifos do documento). 
Esta foi a solução emergencial que o sistema educacional de escolas públicas e privadas julgou a mais acertada frente ao cenário da pandemia, entretanto questões de especificidades dos estudantes não foram salientadas, o que tem gerado intensos debates desde então.

[...] mais da metade dos indivíduos que possuem acesso (à internet) o fazem via telefone celular, dispositivo adequado apenas para uma faixa muito limitada de serviços. Dentro desse grupo, por sua vez, a maioria é cliente de planos pré-pagos, o que em geral significa limitações na qualidade dos dados trafegados. (ANPOCS, 2020, p.7).

A questão de se ter uma internet com conexão estável e aparelhos eletrônicos adequados para acesso às atividades educativas remotas é fator a se considerar para a realização destas pelos estudantes. Entretanto, quando relacionamos o ensino remoto às pessoas com deficiência, vários outros aspectos devem ser pensados para que se obtenha êxito na aprendizagem.

Nas últimas décadas, os direitos sociais e educacionais das pessoas com deficiência estiveram cada vez mais presentes nas políticas públicas brasileiras. Com isso, verificamos uma crescente no número de matrículas de estudantes com deficiência desde a Educação Básica até o Ensino Superior. Foi através destas mudanças na legislação brasileira que ações mais significativas em relação à educação das pessoas com deficiência puderam proporcionar "infraestrutura adequada para ingresso, acesso e permanência" (DUARTE et al., 2013, p.297) destes estudantes. Destacamos o Decreto $n^{\circ} 6.571$ de 17 de setembro de 2008, revogado pelo Decreto no 7.611 de 17 de novembro de 2011, que regulamenta o atendimento educacional especializado (AEE):

Art. 2o A educação especial deve garantir os serviços de apoio especializado voltado a eliminar as barreiras que possam obstruir o processo de escolarização de estudantes com deficiência, transtornos globais do desenvolvimento ${ }^{3}$ e altas habilidades ou superdotação.

$\S 1$ 1o Para fins deste Decreto, os serviços de que trata o caput serão denominados atendimento educacional especializado, compreendido como o conjunto de atividades, recursos de acessibilidade e pedagógicos organizados institucional e continuamente, prestado das seguintes formas:

I - complementar à formação dos estudantes com deficiência, transtornos globais do desenvolvimento, como apoio permanente e limitado no tempo e na frequência dos estudantes às salas de recursos multifuncionais; ou,

\footnotetext{
${ }^{3} \mathrm{O}$ conceito de transtorno global do desenvolvimento surge na década de 60 , baseado nos trabalhos de Rutter e Cohen. (BELISÁRIO JÚNIOR, 2010, p.12). Atualmente o termo transtorno global do desenvolvimento (TGD), que consta na redação do decreto, não é mais utilizado. 0 mesmo se refere ao transtorno do espectro autista (TEA), regulamentado pela Lei no 12.764, de 27 de dezembro de 2012. (BRASIL, 2012b).
} 
II - suplementar à formação de estudantes com altas habilidades ou superdotação. (BRASIL, 2011, p.1-2, grifo do documento).

Segundo Braum e Vianna "o AEE pode ser a garantia de acesso e permanência de alunos com necessidades especiais na escola regular" (2011, p.27), sendo, portanto, um caminho para "otimizar a aquisição de conhecimentos, desenvolvimento de habilidades e atitudes" (BRAUM; VIANNA, 2011, p.10) dos estudantes com deficiência, uma vez que atendem às suas necessidades específicas. A Resolução n.4/2009, do Conselho Nacional de Educação, da Câmara de Educação Básica (BRASIL, 2009), em seu artigo $2^{\circ}$, esclarece que a função do AEE “é complementar ou suplementar a formação do aluno por meio da disponibilização de serviços, recursos de acessibilidade e estratégias que eliminem as barreiras para sua plena participação na sociedade e desenvolvimento de sua aprendizagem".

A referida Resolução, no artigo $5^{\circ}$, aponta que:

$\S 5$ o o AEE é realizado, prioritariamente, na sala de recursos multifuncionais da própria escola ou em outra escola de ensino regular, no turno inverso da escolarização, não sendo substitutivo às classes comuns, podendo ser realizado, também, em centro de Atendimento Educacional Especializado da rede pública ou de instituições comunitárias, confessionais ou filantrópicas sem fins lucrativos, conveniadas com a Secretaria de Educação ou órgão equivalente dos Estados, Distrito Federal ou dos Municípios. (BRASIL, 2009, p.2).

Assim sendo, é no espaço escolar que a maioria destas atividades são desenvolvidas, sejam elas nas salas de recursos multifuncionais ou em centros de Atendimento Educacional Especializado, através do uso de recursos educacionais para a acessibilidade e aprendizagem:

§ 3ㅇ As salas de recursos multifuncionais são ambientes dotados de equipamentos, mobiliários e materiais didáticos e pedagógicos para a oferta do atendimento educacional especializado.

$\S$ 4ㅇ A produção e a distribuição de recursos educacionais para a acessibilidade e aprendizagem incluem materiais didáticos e paradidáticos em Braille, áudio e Língua Brasileira de Sinais - LIBRAS, laptops com sintetizador de voz, softwares para comunicação alternativa e outras ajudas técnicas que possibilitam o acesso ao currículo. (BRASIL, 2011, p.3-4, grifos do documento).

Em virtude do cenário atual da pandemia da COVID-19, com as escolas fechadas e com as atividades educativas sendo realizadas de forma remota, os estudantes com deficiência não têm acesso presencial às salas de recursos multifuncionais nem ao profissional que atua como agente de apoio à inclusão ${ }^{4}$ (que funcionam dentro das unidades escolares). De acordo com o Parecer $N^{\circ} 11 / 2020$ do CNE (BRASIL, 2020b)

\footnotetext{
${ }^{4}$ Este profissional atua diretamente com o estudante com deficiência, dentro da sala de aula de ensino regular, auxiliando-o nas tarefas necessárias e realiza um trabalho em conjunto com o professor regente, inclusive na adaptação de atividades de acordo com as necessidades do educando. Dependendo da rede de ensino, pode receber outra nomenclatura.
} 
"enquanto durar a situação de pandemia, (os estudantes) somente deverão retornar às aulas presenciais ou ao atendimento educacional especializado por indicação da equipe técnica da escola, ou quando os riscos de contaminação estiverem em curva descendente." Além disso, mesmo que o estudante tenha, neste período de distanciamento social, acesso aos recursos educacionais para a acessibilidade, como videoaulas em Língua Brasileira de Sinais, outros estudantes com deficiência podem não ser atendidos, em razão de alguma especificidade decorrente de sua deficiência ou realidade atual enfrentada.

Dentro do quadro de desigualdade em que se encontra a educação remota praticada durante o período de distanciamento social, podemos afirmar que o princípio de igualdade de condições, presente na Lei de Diretrizes e Bases da Educação Nacional (BRASIL, 1996) está sendo respeitado? Se a educação não é acessada com equidade por todos os estudantes, nos vemos frente a outra questão: a realização do ENEM no ano de 2020 deve ser ou não mantida?

\section{EXAMES PARA INGRESSO NO ENSINO SUPERIOR E O ENEM AO LONGO DA HISTÓRIA}

O primeiro exame de seleção para ingresso na faculdade data de 1911, definido pelo decreto $n^{\circ}$ 8.659. (BRASIL, 1911). A aprovação no antigo exame de admissão era obrigatória para a matrícula, sendo, portanto, um "teste", um mecanismo para excluir os alunos que não possuíssem formação adequada para cursar o ensino superior. (BARROS, 2014). Ao longo do século, o vestibular, que recebeu esse nome na Reforma Carlos Maximiliano (BRASIL, 1915), sofreu várias mudanças dentre as quais destacamos a instituição do "vestibular classificatório" através do Decreto $\mathrm{n}^{\circ} 68.908$, de 13 de julho de 1971.

Art. 1ㅇ A admissão aos cursos superiores de graduação será feita mediante classificação, em Concurso Vestibular, dos candidatos que tenham escolarização completa de nível colegial, ou equivalente.

Art. 2o O Concurso Vestibular far-se-á rigorosamente pelo processo classificatório, com o aproveitamento dos candidatos até o limite das vagas fixadas no edital, excluindo-se o candidato com resultado nulo em qualquer das provas.

Parágrafo único. A classificação dos candidatos far-se-á na ordem decrescente dos resultados obtidos no Concurso Vestibular, levando-se em conta a sua formação de grau médio e sua aptidão para prosseguimento de estudos em grau superior. (BRASIL, 1971, p.1).

Nos anos 90, com a aprovação da LDB (BRASIL, 1996) e o aumento dos investimentos em políticas públicas, o acesso à escolarização teve uma crescente considerável. A educação básica passou a ser obrigatória e o Estado incumbido de fornecê-la de forma gratuita. Desta forma, o número de matrículas nesta etapa de ensino teve um alargamento considerável. 
Art. 4ㅇ O dever do Estado com educação escolar pública será efetivado mediante a garantia de: I - ensino fundamental, obrigatório e gratuito, inclusive para os que a ele não tiveram acesso na idade própria; II progressiva extensão da obrigatoriedade e gratuidade ao ensino médio. (BRASIL, 1996, p.2).

Com o aumento do número de estudantes na educação básica, faz-se necessário que o ensino obrigatório e gratuito, ofertado em todo o país, fosse de qualidade. Surge então, através da Portaria Ministerial $n^{\circ}$ 438, de 28 de maio de 1998, o Exame Nacional do Ensino Médio (ENEM), que em seu artigo $1^{\circ}$ se apresenta como "procedimento de avaliação do desempenho do aluno", sendo portanto subsídio para se aprimorar as políticas educacionais, principalmente na rede pública de ensino. 0 referido documento, em seu artigo $2^{\circ}$ dispõe sobre as competências e habilidades a serem desenvolvidas ao longo do ensino fundamental e médio. O caráter avaliativo da educação brasileira pode ser verificado em seu artigo $6^{\circ}$.

Art. 60 O INEP, resguardado o sigilo individual, estruturará um banco de dados e emitirá relatórios com os resultados do ENEM, que estarão disponíveis para as instituições de ensino superior, para as secretarias estaduais de educação e para os pesquisadores, visando ao aprofundamento e à ampliação de análises de interesse da sociedade. (BRASIL, 1998, p.5).

Entretanto, por não se tratar de um exame gratuito na época, os resultados não apresentavam a avaliação fidedigna do desempenho dos estudantes brasileiros. (SANTOS, 2011). Em busca de atingir um número maior de estudantes, o Governo implementou, em 2001, a isenção da taxa de inscrição para estudantes da rede pública de ensino e/ou de baixa renda. Com isso, houve aumento considerável no número de inscrições do exame, passando de pouco mais de 157 mil inscritos em 1998, ano de criação do Enem, para 1.624.131 inscritos em 2001. No ano de 2005, com a instituição do ProUni - Programa Universidade para Todos, Lei $n^{\circ} 11.096$, de 13 de janeiro de 2005, as notas do Enem passaram a ser base para a concessão de bolsas de estudos, parciais e integrais, em instituições privadas de ensino superior e o exame recebeu 3,7 milhões de inscrições em 2006.

Art. 3o 0 estudante a ser beneficiado pelo Prouni será pré-selecionado pelos resultados e pelo perfil socioeconômico do Exame Nacional do Ensino Médio - ENEM ou outros critérios a serem definidos pelo Ministério da Educação, e, na etapa final, selecionado pela instituição de ensino superior, segundo seus próprios critérios, à qual competirá, também, aferir as informações prestadas pelo candidato. (BRASIL, 2005, p.1).

As mudanças no Enem continuaram e em 2009 a avaliação passou a ter 180 questões (das 63 anteriores), além da redação e passou a ser aplicada em 2 dias. Além disso, a Portaria INEP $n^{\circ}$ 109, de 27 de maio de 2009 altera a Portaria MEC no 438, de 28 de maio de 1998 e, conforme verificado em seu artigo $2^{\circ}$, possibilita ao exame sua utilização para a promoção da certificação de conclusão do ensino médio e ser alternativa para acesso ao ensino superior. 
Art. 2o Constituem objetivos do Enem:

I - oferecer uma referência para que cada cidadão possa proceder à sua auto-avaliação com vistas às suas escolhas futuras, tanto em relação ao mundo do trabalho quanto em relação à continuidade de estudos;

II - estruturar uma avaliação ao final da educação básica que sirva como modalidade alternativa ou complementar aos processos de seleção nos diferentes setores do mundo do trabalho;

III - estruturar uma avaliação ao final da educação básica que sirva como modalidade alternativa ou complementar aos exames de acesso aos cursos profissionalizantes, pós-médios e à Educação Superior;

IV - possibilitar a participação e criar condições de acesso a programas governamentais;

V - promover a certificação de jovens e adultos no nível de conclusão do ensino médio nos termos do art. 38, §§ 1 o e 2 o da Lei no 9.394/1996 - Lei das Diretrizes e Bases da Educação Nacional (LDB);

$\mathrm{VI}$ - promover avaliação do desempenho acadêmico das escolas de ensino médio, de forma que cada unidade escolar receba o resultado global;

VII - promover avaliação do desempenho acadêmico dos estudantes ingressantes nas Instituições de Educação Superior. (BRASIL, 2009a, p.1).

Com a utilização do Enem como principal meio de pleito à uma vaga no ensino superior, o exame conquista a cada ano mais inscritos e a seleção destes estudantes se apresenta cada vez mais acirrada. (SANTOS, 2011). Debates em torno de questões igualitárias de políticas públicas vão se intensificando e, no ano de 2012 verificamos a instituição da Lei $\mathrm{n}^{\circ}$ 12.711, que versa sobre a reserva de vagas nas instituições federais de ensino, nos níveis médio e superior, para estudantes que tenham cursado integralmente o ensino fundamental ou médio respectivamente, na rede pública de ensino, autodeclarados pretos, pardos e indígenas.

Essas medidas de promoção de igualdade começaram a ser executadas e, com a aprovação da Lei $n^{\circ} 13.409$ de 28 de dezembro de 2016, as pessoas com deficiência também foram incluídas na reserva de vagas.

Art. 3o Em cada instituição federal de ensino superior, as vagas de que trata o art. 1o desta Lei serão preenchidas, por curso e turno, por autodeclarados pretos, pardos e indígenas e por pessoas com deficiência, nos termos da legislação, em proporção ao total de vagas no mínimo igual à proporção respectiva de pretos, pardos, indígenas e pessoas com deficiência na população da unidade da Federação onde está instalada a instituição, segundo o último censo da Fundação Instituto Brasileiro de Geografia e Estatística - IBGE. (BRASIL, 2016, p.1).

Com base no que foi apresentado, verificamos que atualmente o Enem não é apenas um instrumento de seleção para ingresso nos cursos de graduação das instituições de ensino superior brasileiras, mas é uma espécie de "bússola para a reforma do Ensino Médio" (SANTOS, 2011, p.204), acima de tudo, na promoção de uma educação nacional de qualidade, uma vez que seu objetivo primeiro, presente na portaria de sua 


\section{Edição Especial COVID-19}

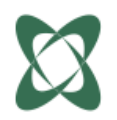

criação é "Art. 1ㅇ․ Instituir o Exame Nacional do Ensino Médio - ENEM, como procedimento de avaliação do desempenho do aluno." (BRASIL, 1998).

Vale destacar também que, devido ao Decreto $n^{\circ} 9.432$ de 29 de junho de 2018, a certificação de Ensino Médio se dará através do Exame Nacional para Certificação de Competências de Jovens e Adultos (ENCCEJA) e não mais pelo Enem, como era feito até então, assim sendo, conforme o decreto supracitado:

Art. 6o O Encceja tem como objetivo aferir as competências e as habilidades de:

I - jovens e adultos que não concluíram o ensino fundamental ou o ensino médio na idade própria;

II - pessoas privadas de liberdade; ou,

III - pessoas que residem no exterior.

Parágrafo único. O Encceja poderá ser utilizado para fins de certificação de níveis de ensino.

Art. 70 O Enem tem como objetivo aferir o domínio das competências e das habilidades esperadas ao final da educação básica.

Parágrafo único. O Enem poderá ser utilizado como mecanismo de acesso à educação superior e aos programas governamentais de financiamento ou apoio ao estudante do ensino superior. (BRASIL, 2018, p.2).

Segundo o calendário divulgado pelo INEP para a realização do Enem 2020, divulgado ainda no ano de 2019, bem antes da pandemia do coronavírus assolar o país, no dia 06 de abril de 2020 se iniciou o prazo para solicitação de isenção da taxa de inscrição do exame e, com isso, começaram também os questionamentos acerca da grande questão: manter a realização do Enem no presente ano letivo seria a melhor solução em meio ao distanciamento social e à realização das atividades educacionais de forma remota, que não alcança toda a população educacional brasileira (ANPOCS, 2020)?

Baseada na necessidade de assegurar chances iguais a todos os estudantes que desejarem realizar a prova do Enem frente ao fechamento das unidades de ensino do país e à vulnerabilidade socioeconômica que impede que o ensino remoto se faça com equidade aos estudantes, a Defensoria Pública da União solicitou através de ação civil pública o adiamento do exame. Em 17 de abril de 2020 a 12 a Vara Cível Federal de São Paulo concedeu a liminar que prevê a adequação do calendário do Exame Nacional do Ensino Médio (Enem) deste ano ao calendário escolar de 2020. O Inep formalizou mudanças no calendário, alterando a aplicação do exame na versão digital para os dias 22 e 29 de novembro (que antes era previsto para 11 e 18 de outubro), porém permaneceu com a data inicial de aplicação da prova impressa para os dia $1^{\circ} \mathrm{e}$ 8 de novembro e a Advocacia-Geral da União recorreu a decisão da liminar.

No dia 29 de abril, argumentando que uma mudança poderia afetar ainda mais os estudantes e atrasar o ingresso no ensino superior, o desembargador federal Antonio 
Cedenho, do TRF-3 (Tribunal Regional Federal da 3ạ Região), suspendeu a liminar que determinava a readequação do calendário do Exame Nacional do Ensino Médio 2020, afirmando que o MEC e o Inep, organizadores da prova, adotaram medidas efetivas para que nenhum candidato seja prejudicado por conta da pandemia, como a prorrogação do prazo do pedido de isenção da taxa de inscrição do exame. (QUINTALTO, 2020).

Intensos debates populares foram travados em relação ao adiamento das provas. No dia 19 de maio o Senado aprovou o projeto que adia o Enem (RESENDE; CARVALHO, 2020), e o texto seguiu para avaliação da Câmara dos Deputados. O ministro da Educação, Abraham Weintraub, que adotava posição contrária ao adiamento, declarou através de nota oficial no dia 20 de maio que o exame seria adiado:

Atento às demandas da sociedade e às manifestações do Poder Legislativo em função do impacto da pandemia do coronavírus no Exame Nacional do Ensino Médio (Enem) 2020, o Instituto Nacional de Estudos e Pesquisas Educacionais Anísio Teixeira (Inep) e o Ministério da Educação (MEC) decidiram pelo adiamento da aplicação dos exames nas versões impressa e digital. As datas serão adiadas de 30 a 60 dias em relação ao que foi previsto nos editais.

Para tanto, o Inep promoverá uma enquete direcionada aos inscritos do Enem 2020, a ser realizada em junho, por meio da Página do Participante. As inscrições para o exame seguem abertas até as $23 \mathrm{~h} 59$ desta sexta-feira, 22 de maio. (INEP, 2020a, p.1).

Em outra nota oficial, publicada pela Assessoria de Comunicação Social (INEP, 2020b) no dia 22 de maio, o Inep informa que os estudantes terão mais cinco dias para efetivar a inscrição no exame, prorrogando até as 23 h59 do dia 27 de maio de 2020.

\section{O EXAME NACIONAL DO ENSINO MÉDIO EM NÚMEROS}

Desde o ano de 2009, quando o Enem passou - através da Portaria INEP $\mathrm{n}^{\circ} 109$ - a ser alternativa para certificação de conclusão do ensino médio e/ou para acesso ao ensino superior, o Inep fornece em sua página oficial de internet as Sinopses Estatísticas referentes ao exame. Tal publicação “corresponde a um conjunto de tabelas com informações coletadas junto aos inscritos, por meio do Questionário Socioeconômico, e pela aplicação do Exame em si. As informações são organizadas por região geográfica e unidade da federação." (INEP, 2009, p.1). Iniciamos agora a apreciação de alguns dados das Sinopses Estatísticas do Exame Nacional do Ensino Médio (Enem). O foco neste momento é apresentar a evolução em números relacionada às inscrições do exame ao longo dos anos, além de discutir questões acerca da participação dos estudantes com deficiência no Enem.

Os dados das Sinopses Estatísticas do Enem indicam que as inscrições para a realização do exame cresceram gradualmente, conforme verificado no gráfico 1, com picos entre 2013 e 2016, possivelmente relacionados à instituição da Lei $n^{\circ} 12.711$, que versa sobre a reserva de vagas nas Instituições Federais de Ensino Superior 
(IFES). Em vista disso, um número maior de estudantes pode ter procurado realizar o exame em busca de pleitear uma vaga nas IFES. Em contrapartida, verificamos um declínio nas inscrições a partir de 2017, o que pode indicar que estudantes que buscavam no Enem a certificação do ensino médio, agora devido ao Decreto $n^{\circ} 9.432$ (BRASIL, 2018), buscam tal certificação através do Encceja.

Gráfico 1 - Número total de inscritos no

Exame Nacional do Ensino Médio (2009-2018).

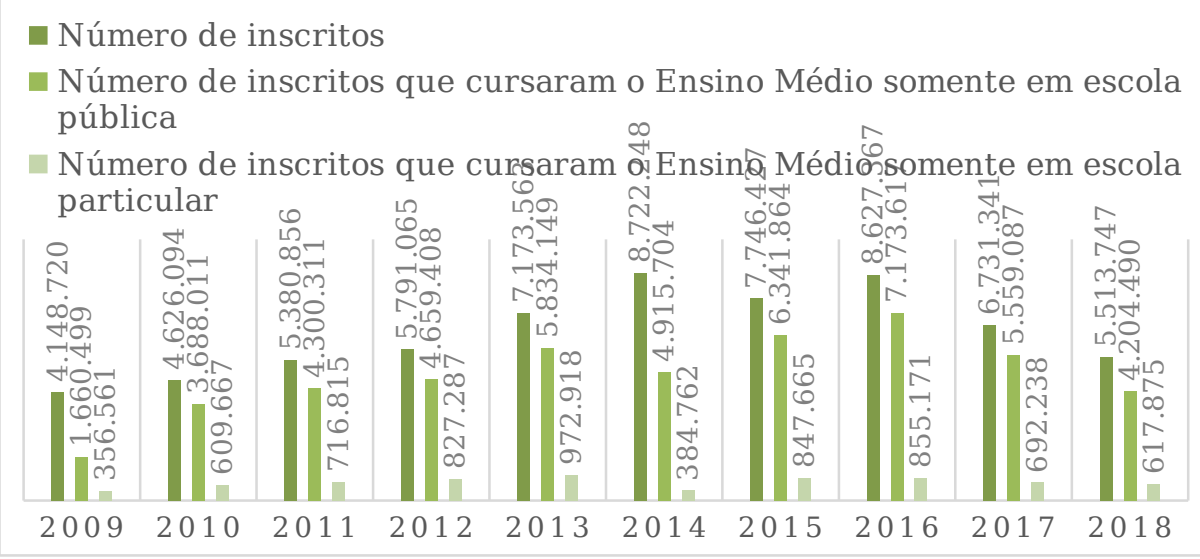

Fonte: elaborado pelas autoras com base nas Sinopses Estatísticas do

Exame Nacional do Ensino Médio (Enem) do INEP (2009-2018).

Entretanto o número de inscritos não apresenta a totalidade de estudantes que realizam as provas e que podem, então, pleitear a tão sonhada vaga no ensino superior. Diversos fatores implicam na não realização das provas que, são realizadas em dois dias. Apresentamos, no gráfico 2, a relação entre o número de inscritos e o número de inscritos presentes nos 2 dias de provas, o que evidencia números bastante distintos, com declínio aproximado de 30\%, neste quantitativo.

Nos últimos meses presenciamos um grande debate popular nas redes sociais e mídias de rádio e televisão envolvendo o Enem: a questão de adiar as provas de 2020, programadas para os dias 1 e 8 de novembro. Tal fato se deu em virtude das aulas remotas não alcançarem toda a população estudantil de igual maneira, conforme salientado pelo Parecer CNE/CP n 5/2020, uma vez que essa foi a solução emergencial para a educação em meio à pandemia do coronavírus.

“É importante considerar as fragilidades e desigualdades estruturais da sociedade brasileira que agravam o cenário decorrente da pandemia em nosso país, em particular na educação, se observarmos as diferenças de proficiência, alfabetização e taxa líquida de matrícula relacionados a fatores socioeconômicos e étnico-raciais. Também, como parte desta desigualdade estrutural, cabe registrar as diferenças existentes em relação às condições de acesso ao mundo digital por parte dos estudantes e de suas famílias. Além disso, é relevante observar as consequências socioeconômicas que resultarão dos 
impactos da COVID-19 na economia como, por exemplo, aumento da taxa de desemprego e redução da renda familiar. Todos estes aspectos demandam um olhar cuidadoso para as propostas de garantia dos direitos e objetivos de aprendizagem neste momento a fim de minimizar os impactos da pandemia na educação. (BRASIL, 2020a, p.3).

Gráfico 2 - Número total de inscritos e Número de inscritos presentes nos 2 dias de provas no Exame Nacional do Ensino Médio (2009-2018).

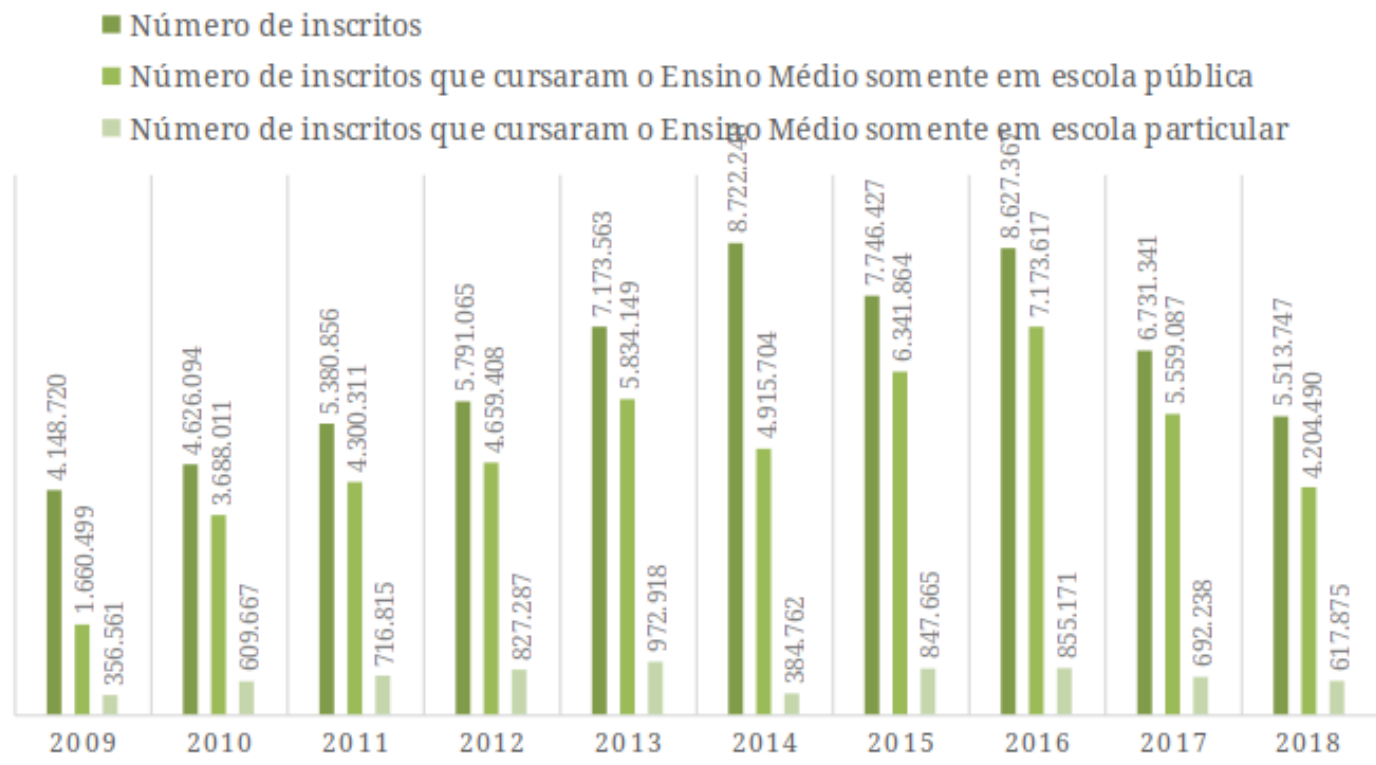

Fonte: elaborado pelas autoras com base nas Sinopses Estatísticas do Exame Nacional do Ensino Médio (Enem) do INEP (2009-2018).

O principal impasse foi em relação aos estudantes de baixa renda, oriundos de escola pública, não terem as mesmas condições de acesso à internet que os estudantes de escolas particulares. No gráfico 3 podemos verificar que a maioria dos estudantes que se inscrevem ao longo dos anos para realizar as provas do Enem são oriundos do Ensino Médio em rede pública de ensino.

A partir do gráfico 3, verificamos que na maioria das vezes a relação de inscritos oriundos do ensino médio cursado somente em escola pública chegou a $80 \%$ do número total de inscritos, o que vem ratificar a necessidade de adiamento do exame no ano de 2020 em vista da situação socioeconômica de grande parte dos estudantes que se inscrevem no Enem, visto que estes não possuem condições de acesso à internet, computadores e/ou tablets para acompanhar, satisfatoriamente, as aulas remotas durante o período de distanciamento social. (FOLHA DE SÃO PAULO, 2020).

Há também uma outra parcela da população socialmente invisível (DI BLASI; DUTRA; RUMJANEK, 2019), que por muitas vezes é esquecida e não se faz diferente neste cenário de distanciamento social em que nos encontramos: as pessoas com deficiência. Excluídas no passado e privadas do direito à educação, desde a 
Constituição Federal de 1988, garantem esses direitos, por força de lei, porém, por diferentes motivos de acesso e acessibilidade, também encontram dificuldades em relação a educação remota. Além disso, segundo Araujo e Fernandes (2020, p.5.477), "o grupo de pessoas com deficiência não se constitui como isolado de um contexto social e poderemos então ter vulnerabilidades ainda acrescidas como por exemplo [...] ter uma deficiência e viver em espaços insalubres e sem condições sanitárias". O gráfico 4 apresenta o número de inscritos no Enem com necessidade especial declarada 5 .

Gráfico 3 - Número total de inscritos no Exame Nacional do Ensino Médio e Número de inscritos que cursaram o Ensino Médio. somente em escola pública e somente em escola particular (2009-2018).

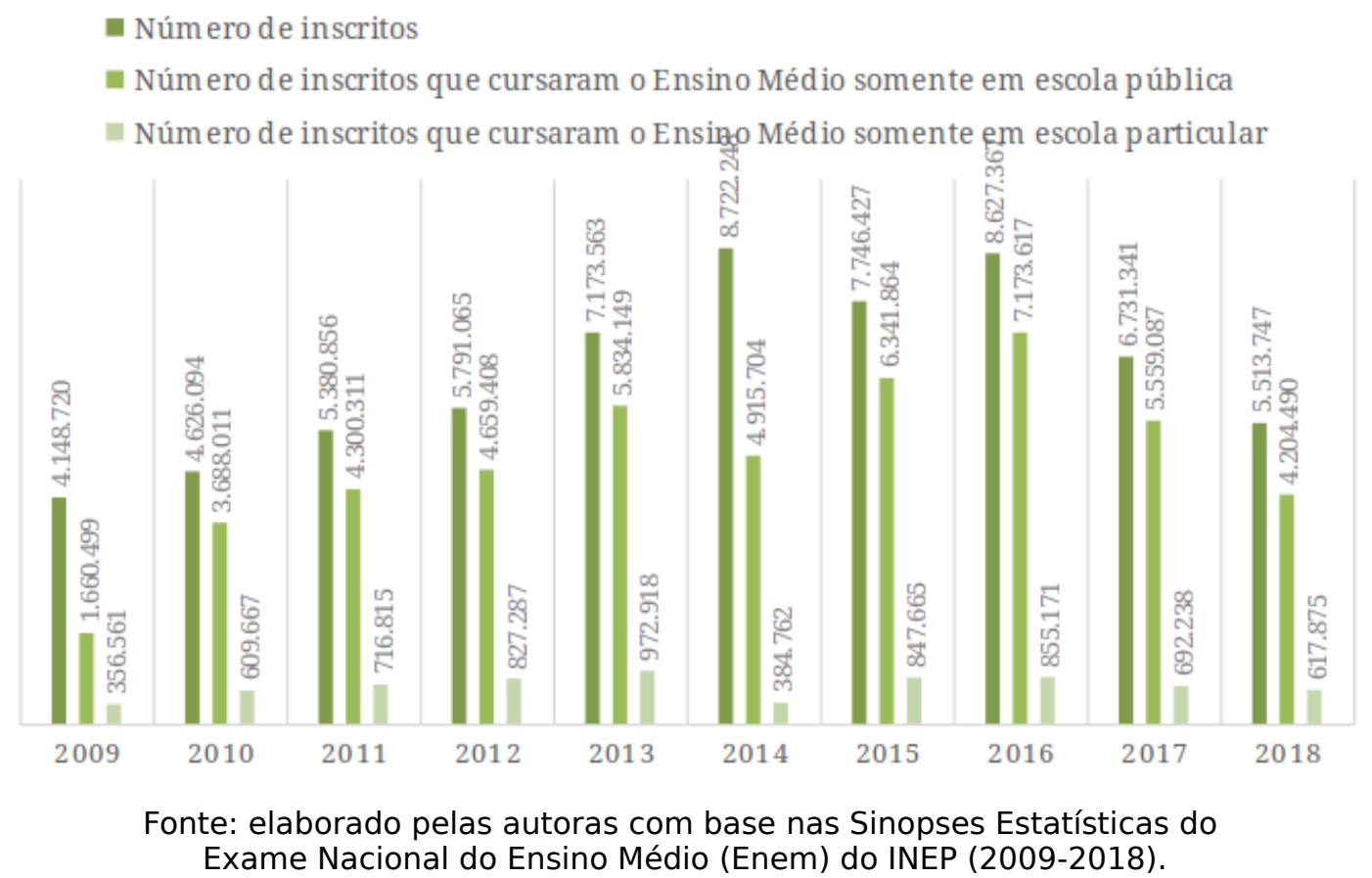

Ao analisarmos o gráfico 4 verificamos uma crescente no número de inscrições de pessoas com necessidades especiais a partir do ano de 2013, com ápice de inscritos no ano de 2016. Tal evento pode estar relacionado ainda à instituição da lei $n^{\circ} 12.711$, que versa sobre a reserva de vagas para autodeclarados pretos, pardos e indígenas nas IFES, mesmo que não ainda com reserva destinada especificamente às pessoas com deficiência.

\footnotetext{
${ }^{5}$ A Sinopse Estatística do Enem agrupa na tabela de inscritos por necessidade especial declarada as deficiências conforme a LBI (2015) - baixa visão, deficiência visual, surdez, deficiência auditiva, surdocegueira, deficiência física, deficiência intelectual e TEA (transtorno do espectro autista) - e os transtornos de aprendizagem - déficit de atenção, dislexia e discalculia.
} 
Gráfico 4 - Número de inscritos com necessidade especial declarada no Exame Nacional do Ensino Médio (2010-2018).

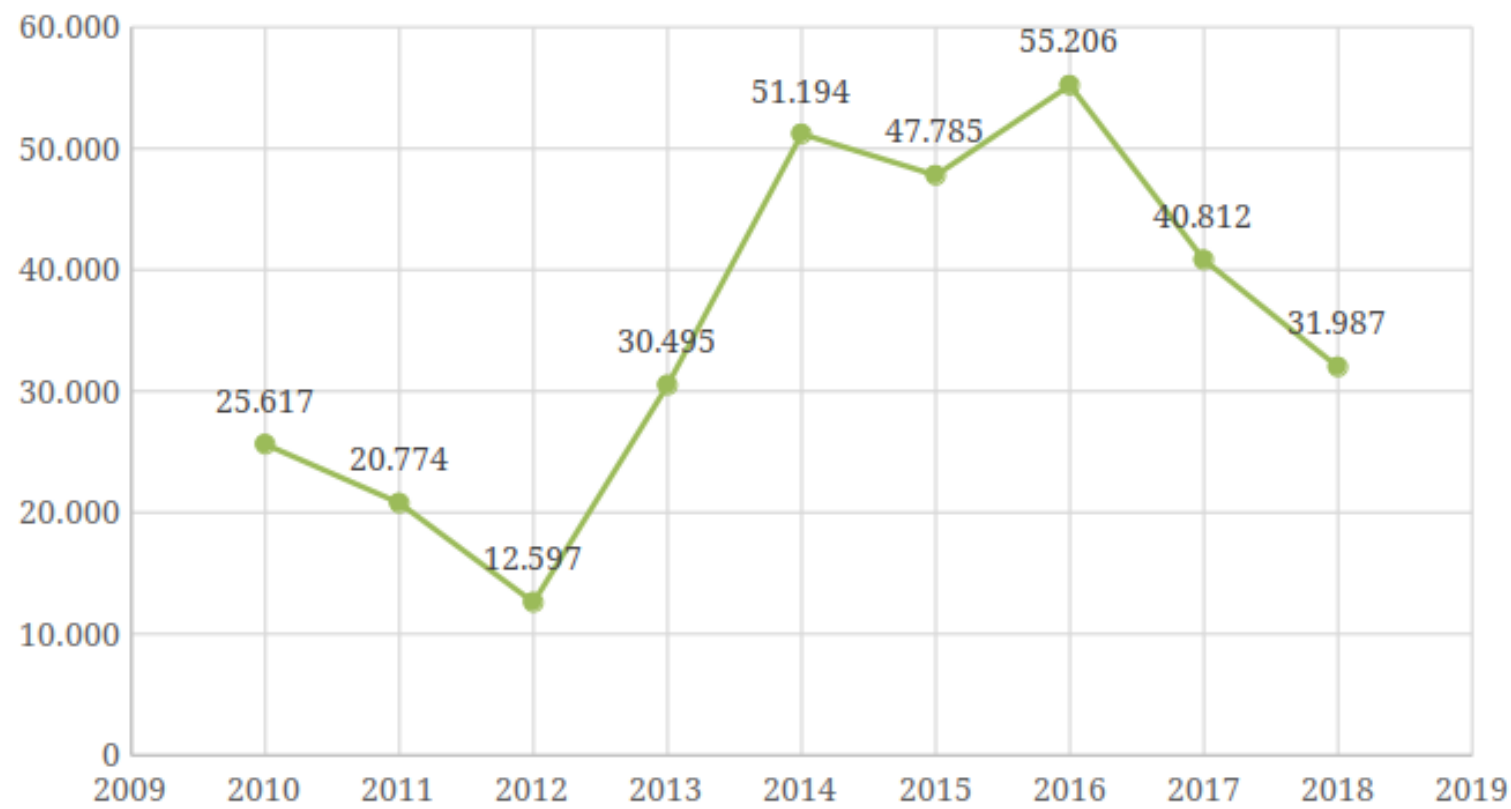

Fonte: elaborado pelas autoras com base nas Sinopses Estatísticas do Exame Nacional do Ensino Médio (Enem) do INEP (2010-2018) ${ }^{6}$.

O fato de o maior número de inscrições de pessoas com necessidades especiais estar centrado no ano de 2016 pode ter relação direta também com a instituição da Lei Brasileira de Inclusão da Pessoa com Deficiência (LBI) no ano de 2015. (BRASIL, 2015). Ao assegurar em condições de igualdade o exercício da cidadania da pessoa com deficiência, a Lei $n^{\circ}$ 13.146, de 6 de janeiro de 2015, em seu artigo 30, nos apresenta medidas a serem adotadas nos processos seletivos para ingresso no ensino superior, dentre estes, o Enem:

Nos processos seletivos para ingresso e permanência nos cursos oferecidos pelas instituições de ensino superior e de educação profissional e tecnológica, públicas e privadas, devem ser adotadas as seguintes medidas:

I - atendimento preferencial à pessoa com deficiência nas dependências das Instituições de Ensino Superior (IES) e nos serviços;

II - disponibilização de formulário de inscrição de exames com campos específicos para que o candidato com deficiência informe os recursos de acessibilidade e de tecnologia assistiva necessários para sua participação;

III - disponibilização de provas em formatos acessíveis para atendimento às necessidades específicas do candidato com deficiência;

\footnotetext{
${ }^{6}$ A Sinopse Estatística do Enem do ano de 2009 não apresentou a tabela de inscritos por necessidade especial declarada.
} 


\section{Edição Especial COVID-19}

IV - disponibilização de recursos de acessibilidade e de tecnologia assistiva adequados, previamente solicitados e escolhidos pelo candidato com deficiência;

V - dilação de tempo, conforme demanda apresentada pelo candidato com deficiência, tanto na realização de exame para seleção quanto nas atividades acadêmicas, mediante prévia solicitação e comprovação da necessidade;

VI - adoção de critérios de avaliação das provas escritas, discursivas ou de redação que considerem a singularidade linguística da pessoa com deficiência, no domínio da modalidade escrita da língua portuguesa;

VII - tradução completa do edital e de suas retificações em Libras.

(BRASIL, 2015, p.31).

A disponibilização de provas em formatos acessíveis, uso de recursos de tecnologia assistiva e dilação do tempo de realização do exame, de acordo com a necessidade específica de cada candidato evidenciam a busca pela universalização do acesso de todos em iguais condições na realização do exame. Sabemos que a garantia por lei não determina que esses direitos sejam efetivamente cumpridos (DUARTE et al., 2013), por isso a luta nunca termina e devemos estar sempre atentos às necessidades específicas de cada estudante, com vistas a garantir um sistema educacional inclusivo. (BRASIL, 2014). Assim sendo, conjecturamos que o não adiamento das provas do Enem 2020 implicaria na perda de condições de igualdade para alguns estudantes, incluindo aqui os estudantes com deficiência, o que seria um retrocesso histórico para eles.

Sabemos que a questão da "inclusão digital" nos tempos de distanciamento social e de aulas remotas é fator questionável em relação a não atingir toda a população de estudantes no país, uma vez que, segundo dados da Pesquisa Nacional por Amostra de Domicílios Contínua/IBGE, realizada no ano de 2018, apenas 74,7\% dos domicílios brasileiros tinham acesso à internet. (IBGE, 2018, p.1).

O direito à educação escolar pública é dever do Estado, conforme nos versa a LDB. Segundo o capítulo III, art. $4^{\circ}$, inciso IX da referida lei é seu dever garantir "padrões mínimos de qualidade de ensino, definidos como a variedade e quantidade mínimas, por aluno, de insumos indispensáveis ao desenvolvimento do processo de ensinoaprendizagem." (BRASIL, 1996). É válido destacar que, neste momento, mesmo com as aulas ministradas no formato remoto, nem sempre o estudante possui os insumos indispensáveis ao desenvolvimento do processo de ensino-aprendizagem, o que gera uma desvantagem para vários estudantes, visto que há ainda parte da população estudantil sem acesso à internet que garanta uma conexão estável e/ou aparelhos eletrônicos necessários ao ensino remoto. (OLIVEIRA et al., 2020).

Ilustramos o fato com o discurso da reitora da UFRJ, Denise Pires de Carvalho, em entrevista ao Jornal O Globo, versando sobre questões referentes ao planejamento das atividades acadêmicas pós-pandemia e o adiamento do Exame Nacional do Ensino 
Médio. Em sua fala, salientou a impossibilidade de realização do exame tendo em vista o fechamento das escolas frente à pandemia da COVID-19 e outros aspectos:

Impossível o Enem ser realizado em novembro em cidades como o Rio de Janeiro. Aqui não teremos, provavelmente, escolas completamente abertas. Como fazer as provas? Todos com o EPI? Difícil. Era um pouco irresponsável manter em novembro. Não só pela dificuldade de estudo, mas pelo local da prova. Não pode colocar todas em ambiente fechado. (ALFANO, 2020, p.1).

Quando questionada sobre as aulas presenciais no ano de 2020, em sua resposta a reitora evidencia também a problemática da inclusão digital, que no Brasil ainda precisa de maiores investimentos.

As atividades presenciais para o semestre são imaginadas para turmas menores. Aquele estudante com dificuldade de acesso à internet. Mesmo a UFRJ fazendo um esforço de inclusão digital, há endereços nos quais a banda larga não chega. O Rio tem uma geografia muito especial. (ALFANO, 2020, p.1).

Com uma geografia única, o Estado do Rio de Janeiro possui ainda localidades que não tem acesso à banda larga, onde muitas vezes a rede de dados móveis fornecida pelas operadoras de telefonia celular também não é satisfatória. Se até na capital metropolitana temos momentos de instabilidade de conexão, é visível que o modelo de educação remota atual não atinge à todos os estudantes, principalmente os da rede pública de ensino, que muitas das vezes não têm condições de manter os custos para se obter conexão de internet. (OLIVEIRA et al., 2020).

\section{CONSIDERAÇÕES FINAIS}

A educação remota em tempos de pandemia é um debate constante, não se esgota aqui. A prova do Enem foi adiada, sem data definida, assim como não temos data definida para o fim do distanciamento social, que ainda pode durar dias, semanas ou meses; não é possível prever a evolução do vírus no país. Porém, o adiamento da prova não soluciona os problemas que grande parte dos estudantes enfrentam de falta de estrutura para o acompanhamento das aulas remotas. O problema que envolve a desigualdade econômica brasileira só se agrava ainda mais com a crise gerada pelo coronavírus. Permanecer conectado e estudando "normalmente" têm sido inviável para um número cada vez maior de estudantes.

As especificidades de cada estudante com deficiência podem ser muitas, e únicas. Em vistas a toda realidade atual, muitos tratamentos e terapias podem ter sido interrompidos, o que, de certa forma, afeta diretamente o estudo destes. Como já salientado anteriormente, as salas de recursos multifuncionais estão fechadas e muitas vezes o atendimento remoto requer apoio de recursos tecnológicos que podem não ser dominados (ou até mesmo financeiramente possíveis) pelos estudantes e/ou responsáveis, causando dificuldades no processo de desenvolvimento da aprendizagem. Cada pessoa com deficiência é única, e com isso precisa de 
intervenções específicas. Acreditar que a educação remota atende a todos é ilusório, pois o país não estava preparado para tal mudança.

O governo pede que os estudantes se reinventem e continuem estudando. Mesmo com o exame adiado e sem projeção de data para a sua realização, as inscrições continuaram e a propaganda é vinculada através das mídias sociais, televisão e rádio. Este mesmo governo exige que os professores se reinventem, que produzam aulas, que não deixem a educação "parar". A educação precisa se reinventar sim, para atingir a todos, sem distinção. Afinal, "a educação só será para todos, se for para cada um." (SOUZA, 2018, p.46).

\section{REFERÊNCIAS}

ALFANO, Bruno. "Ou encontramos medicação para a COVID-19 ou não haverá retorno completo" em 2020, diz reitora da UFRJ. O Globo, Rio de Janeiro, 27 mai. 2020.

Disponível em: <https://oglobo.globo.com/sociedade/coronavirus/ou-encontramosmedicacao-para-covid-19-ou-nao-havera-retorno-completo-em-2020-diz-reitora-daufrj-24438673>. Acesso em: 01 jun. 2020.

ANPOCS, Associação Nacional de Pós-Graduação em Ciências Sociais. Cientistas sociais e o coronavírus. São Paulo, boletim especial n³6, p.1-11, 08 mai. 2020. Disponível em: <http://www.anpocs.com/index.php/ciencias-sociais/destaques/2350boletim-n-36-cientistas-sociais-e-o-coronavirus >. Acesso em: 16 mai. 2020.

ARAUJO, Luiz Antonio Souza de; FERNANDES, Edicléa Mascarenhas. O cuidado com pessoas com deficiência em tempos do COVID-19: considerações acerca do tema. Brazilian Journal of Health Review, Curitiba, v.3, n.3, mai./jun. 2020.

BARROS, Aparecida da Silva Xavier. Vestibular e Enem: um debate contemporâneo. Ensaio: Avaliação e Políticas Públicas em Educação, Rio de Janeiro, v.22, n.85, p.1057-1090, dez. 2014.

BELISÁRIO JÚNIOR, José Ferreira. A Educação Especial na Perspectiva da Inclusão Escolar: transtornos globais do desenvolvimento. Brasília: MEC/SEESP; Fortaleza: Universidade Federal do Ceará, 2010. Disponível em:

$<$ http://www.mpgo.mp.br/portalweb/hp/41/ docs/a_educacao_especial_na_perspectiva_da_inclusao_escolar.pdf $>$. Acesso em: 08 jun. 2020.

BRASIL. [Constituição (1988)]. Emenda Constitucional $\mathbf{n}^{\circ} \mathbf{1 9}$, de 4 de junho de 1998. Brasília, DF: Presidência da República, [1998]. Disponível em: <http://www.planalto.gov.br/ccivil_03/Constituicao/Emendas/Emc/emc19.htm>. Acesso em: 30 abr. 2020.

BRASIL. Decreto $\mathbf{n}^{\circ} \mathbf{1 1 . 5 3 0}$ de 18 de março de 1915. Reorganiza o ensino secundário e o superior na República. Brasília, DF: Presidência da República, 1915. Disponível em: <https://www2.camara.leg.br/legin/fed/decret/1910-1919/decreto- 
11530-18-marco-1915-522019-republicacao-97760-pe.html>. Acesso em: 30 mai. 2020 .

BRASIL. Decreto $\mathbf{n}^{\circ} \mathbf{6 8} .908$ de 13 de julho de 1971. Dispõe sobre Concurso Vestibular para admissão aos cursos superiores de graduação. Brasília, DF: Presidência da República, [1971]. Disponível em:

<https://presrepublica.jusbrasil.com.br/legislacao/ 115157/decreto-68908-71>. Acesso em: 30 mai. 2020.

BRASIL. Decreto $n^{\circ} 7.611$ de 17 de novembro de 2011. Dispõe sobre a educação especial, o atendimento educacional especializado e dá outras providências. Brasília, DF: Presidência da República, [2011]. Disponível em:

<http://www.mpsp.mp.br/portal/page/portal/Educacao/Legislacao/Federal/

Decreto_no 7611_171111_EducaçãoEspecial.pdf>. Acesso em: 30 mai. 2020.

BRASIL. Decreto n 8.659 de 05 de abril de 1911. Aprova a lei Orgânica do Ensino Superior e do Fundamental na República. Brasília, DF: Presidência da República, [1911]. Disponível em:

<https://www2.camara.leg.br/legin/fed/decret/1910-1919/decreto-8659-5-abril-1911517247-publicacaooriginal-1-pe.html>. Acesso em: 30 mai. 2020.

BRASIL. Decreto $\mathbf{n}^{\circ}$ 9.432, de 29 de junho de 2018. Regulamenta a Política Nacional de Avaliação e Exames da Educação Básica. Brasília, DF: Presidência da República, [2018]. Disponível em: <http://www.planalto.gov.br/ccivil_03/Ato20152018/2018/Decreto/ D9432.htm>. Acesso em: 25 mai. 2020.

BRASIL. Lei no 11.096, de 13 de janeiro de 2005. Institui o Programa Universidade para Todos - PROUNI, regula a atuação de entidades beneficentes de assistência social no ensino superior; altera a Lei no 10.891, de 9 de julho de 2004, e dá outras providências. Brasília, DF: Presidência da República, [2005]. Disponível em: <http://www.planalto.gov.br/ccivil_03/_ato2004-2006/2005/lei//11096.htm>. Acesso em: 30 abr. 2020.

BRASIL. Lei no 12.711, de 29 de agosto de 2012. Dispõe sobre o ingresso nas universidades federais e nas instituições federais de ensino técnico de nível médio e dá outras providências. Brasília, DF: Presidência da República, [2012a]. Disponível em: <http://www.planalto. gov.br/ccivil 03/ ato2011-2014/2012/lei//12711.htm>. Acesso em: 30 abr. 2020.

BRASIL. Lei no 12.764, de 27 de dezembro de 2012. Institui a Política Nacional de Proteção dos Direitos da Pessoa com Transtorno do Espectro Autista; e altera o § 3ㅇ do art. 98 da Lei no 8.112, de 11 de dezembro de 1990. Brasília, DF: Presidência da República, [2012b]. Disponível em: <http://www.planalto.gov.br/ccivil_03/Ato20112014/2012/Lei/L12764.htm>. Acesso em: 08 jun. 2020.

BRASIL. Lei no 13.005, de 25 de junho de 2014. Aprova o Plano Nacional de Educação - PNE e dá outras providências. Brasília, DF: Presidência da República, [2014]. Disponível em: <http://www.planalto.gov.br/ccivil_03/ato2011-2014/2014/lei/ 113005.htm >. Acesso em: 30 abr. 2020. 
BRASIL. Lei no 13.146, de 6 de julho de 2015. Institui a Lei Brasileira de Inclusão da Pessoa com Deficiência (Estatuto da Pessoa com Deficiência). Brasília, DF: Presidência da República, [2015]. Disponível em: $<$ http://violenciaedeficiencia.sedpcd.sp.gov.br/pdf/documentos/ LBI.pdf > . Acesso em: 30 abr. 2020.

BRASIL. Lei no 13.409, de 28 de dezembro de 2016. Altera a Lei № 12.711, de 29 de agosto de 2012, para dispor sobre a reserva de vagas para pessoas com deficiência nos cursos técnico de nível médio e superior das instituições federais de ensino. Brasília, DF: Presidência da República, [2016]. Disponível em: <http://www.planalto.gov.br/ ccivil_03/_ato2015-2018/2016/lei/L13409.htm>. Acesso em: 30 abr. 2020.

BRASIL. Lei no 9.394 de 20 de dezembro de 1996. Estabelece as diretrizes e bases da educação nacional. Brasília, DF: Presidência da República, [1996]. Disponível em: <http://www.planalto.gov.br/ccivil_03/leis//9394.htm>. Acesso em: 30 mai. 2020.

BRASIL. Medida Provisória $\mathbf{n}^{\circ} 934$ de 01 de abril de 2020. Estabelece normas excepcionais sobre o ano letivo da educação básica e do ensino superior decorrentes das medidas para enfrentamento da situação de emergência de saúde pública de que trata a Lei no 13.979, de 6 de fevereiro de 2020. Brasília, DF: Presidência da República, [2020]. Disponível em:

$<$ http://www.planalto.gov.br/ccivil_03/_ato2019-2022/2020/mpv/mpv934.htm>. Acesso em: 30 mai. 2020.

BRASIL. Parecer CNE n $^{\circ} 05$ de 28 de abril de 2020. Reorganização do Calendário Escolar e da possibilidade de cômputo de atividades não presenciais para fins de cumprimento da carga horária mínima anual, em razão da Pandemia da COVID-19. Brasília, DF: Presidência da República, [2020a]. Disponível em: $<$ http://portal.mec.gov.br/conselho-nacional-de-educacao/atos-normativos--sumulaspareceres-e-resolucoes/33371-cne-conselho-nacional-de-educacao/85201-parecer-cp2020>. Acesso em: 30 mai. 2020.

BRASIL. Parecer CNE n $^{\circ} 11$ de 07 de julho de 2020. Orientações Educacionais para a Realização de Aulas e Atividades Pedagógicas Presenciais e Não Presenciais no contexto da Pandemia. Brasília, DF: Presidência da República, [2020b]. Disponível em: <http://portal.mec.gov.br/conselho-nacional-de-educacao/atosnormativos--sumulas-pareceres-e-resolucoes/33371-cne-conselho-nacional-deeducacao/85201-parecer-cp-2020>. Acesso em: 27 jul. 2020.

BRASIL. Portaria INEP n 109 de 27 de maio de 2009. Estabelece a sistemática para a realização do Exame Nacional do Ensino Médio. Brasília, DF: Presidência da República, [2009a]. Disponível em: <https://www.legisweb.com.br/legislacao/?

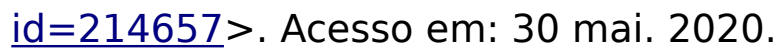


BRASIL. Portaria INEP n 147, de 04 de setembro de 2008. Regulamenta o art. 3은 da Portaria Ministerial no 3.415, de 21 de outubro de 2004, no que tange à fundamentação teórico-metodológica do Exame Nacional para Certificação de Competências de Jovens e Adultos - ENCCEJA. Brasília, DF: Presidência da República, [2008]. Disponível em: <https://www.legisweb.com.br/legislacao/?id=206924>. Acesso em: 25 mai. 2020.

BRASIL. Portaria MEC n 438 de 28 de maio de 1998. Institui o Exame Nacional do Ensino Médio - ENEM. Brasília, DF: Presidência da República, [1998]. Disponível em: <https://www.normasbrasil.com.br/norma/portaria-438-1998_181137.html>. Acesso em: 30 mai. 2020.

BRASIL. Resolução $\mathbf{n}^{\circ}$ 4, de 2 de outubro de 2009. Institui Diretrizes Operacionais para o Atendimento Educacional Especializado na Educação Básica, modalidade Educação Especial. Brasília, DF: Presidência da República, [2009b]. Disponível em: <http://portal.mec.gov.br/ dmdocuments/rceb004_09.pdf>. Acesso em: 25 mai. 2020.

BRAUM, Patrícia; VIANNA, Márcia Marin. Atendimento educacional especializado, sala de recursos multifuncionais e plano de ensino individualizado: desmembramentos de um fazer pedagógico. In: PLETSCH, M. D.; DAMASCENO, A. (Orgs). Educação especial e inclusão escolar: reflexões sobre o fazer pedagógico. Seropédica, RJ: EDUR, p.2334, 2011.

DI BLASI, Felipe; DUTRA, Flávia; RUMJANEK, V. D. B. Affirmative actions and new challenges for higher education at Federal University of Rio de Janeiro. Proceedings of ICERI2019 Conference 11th-13th, November 2019, Seville, Spain, p.5938 - 5942.

DUARTE, Emerson Rodrigues et al. Estudo de caso sobre a inclusão de alunos com deficiência no Ensino Superior. Revista brasileira de educação especial, Marília, v.19, n. 2, p.289-300, jun. 2013.

GIL, Antônio Carlos. Como elaborar projetos de pesquisa. 4. ed. São Paulo: Atlas, 2002.

IBGE. Diretoria de Pesquisas. Coordenação de Trabalho e Rendimento. Pesquisa Nacional por Amostra de Domicílios Contínua. Brasília: IBGE, 2018.

INEP. Nota Oficial - Adiamento do Enem 2020. Brasília: Inep, 2020a.

INEP. Nota Oficial - Inscrições para o Enem 2020 serão prorrogadas até 27 de maio. Brasília: Inep, 2020b.

INEP. Sinopse Estatísticas do Exame Nacional de Ensino Médio 2009. Brasília: Inep, 2009.

INEP. Sinopse Estatísticas do Exame Nacional de Ensino Médio 2010. Brasília: Inep, 2010.

INEP. Sinopse Estatísticas do Exame Nacional de Ensino Médio 2011. Brasília: Inep, 2011. 
INEP. Sinopse Estatísticas do Exame Nacional de Ensino Médio 2012. Brasília: Inep, 2012.

INEP. Sinopse Estatísticas do Exame Nacional de Ensino Médio 2013. Brasília: Inep, 2013.

INEP. Sinopse Estatísticas do Exame Nacional de Ensino Médio 2014. Brasília: Inep, 2014.

INEP. Sinopse Estatísticas do Exame Nacional de Ensino Médio 2015. Brasília: Inep, 2015.

INEP. Sinopse Estatísticas do Exame Nacional de Ensino Médio 2016. Brasília: Inep, 2016.

INEP. Sinopse Estatísticas do Exame Nacional de Ensino Médio 2017. Brasília: Inep, 2017.

INEP. Sinopse Estatísticas do Exame Nacional de Ensino Médio 2018. Brasília: Inep, 2018.

OLIVEIRA, Maria Auxiliadora Monteiro et al. Pandemia do Coronavírus e seus impactos na área educacional. Pedagogia em Ação, Belo Horizonte, v.13, n.1, p.17-24, jan./jun. 2020.

PLETSCH, Márcia Denise. Educação Especial e Inclusão Escolar: uma radiografia do atendimento educacional especializado nas redes de ensino da Baixada Fluminense /RJ. Ciências Humanas e Sociais em Revista, Rio de Janeiro, v.34, n.1, p.31-48, jan./jun. 2012.

QUINTALTO, Rosangela. Calendário do Enem 2020 está mantido, decide justiça. VestibulandoWeb, Minas Gerais, 2 mai. 2020. Disponível em: < https://www. vestibulandoweb.com.br/educacao/enem/calendario-do-enem-2020-esta-mantido/>. Acesso em: 16 mai. 2009.

RESENDE, Sara; CARVALHO, Letícia. Senado aprova projeto que adia Enem. G1, Brasília, 19 mai. 2020. Disponível em:

$<$ https://g1.globo.com/politica/noticia/2020/05/19/senado-aprova-texto-base-deprojeto-que-adia-enem.ghtml>. Acesso em: 27 jul. 2020.

SANTOS, Jean Mac Cole Tavares. Exame Nacional do Ensino Médio: entre a regulação da qualidade do Ensino Médio e o vestibular. Educar em revista, Curitiba, n.40, p.195-205, jun. 2011.

SOUZA, Marisa Mendes Machado de. Deficiência Intelectual e adequações pedagógicas: uma perspectiva a partir do desenho universal para a aprendizagem. 2018. 182 f. Dissertação (Mestrado Profissional em Diversidade e Inclusão) - Universidade Federal Fluminense, Niterói, 2018.

Submetido em: 24/06/2020

Aceito em: 26/08/2020 